\title{
AWARENESS OF PHYSIOTHERAPY \& ITS SCOPE AMONG WOMEN IN A COMMUNITY- A SURVEY
}

\section{Smruti Swagatika Dash.}

MPT(Musculoskeletal \& Sports Physiotherapy), Associate Professor, Narayana Hrudayalaya Institute of Physiotherapy, Bangalore-560099, Karnataka, India.

\section{ABSTRACT}

Background: Physiotherapy is an emerging field in healthcare with innumerable benefits. Talking about its role in women's life $\&$ health, it is again countless. But it has been seen in most of the scenario that women even in the metropolis are not much aware as to when to seek help from a physiotherapist. So the aim of this study was to find out the awareness and knowledge about physiotherapy in women residing in a community.

Methodology: A community based survey was carried out purely based on the questionnaire method which consist of sets of questions. Prior to the data collection the researcher explained about the study to the subject and an informed consent was obtained from them. The researcher gave the questionnaire form to the subject and was required to fill the frame.

Results: Only $79 \%$ of respondents had awareness about physiotherapy but the awareness about scopes \& scenarios in which women can actually benefit from physiotherapy was less.

Conclusion: The result of the study indicates that women in city are still not completely aware of scopes of physiotherapy service. They just know it is a kind of health care service. Appropriate measures have to be taken to increase the awareness and create a good attitude towards the Physiotherapy profession.

KEY WORDS: Women's Health, Physiotherapy, Physiotherapy Awareness.

Address for correspondence: Dr. Smruti Swagatika Dash (PT), MPT(Musculoskeletal \& Sports Physiotherapy), Associate Professor, Narayana Hrudayalaya Institute of Physiotherapy, Bangalore560099, Karnataka, India. E-Mail: ssdashpt@gmail.com

\section{Access this Article online}

Quick Response code

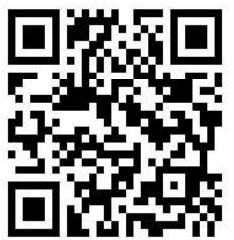

DOI: $10.16965 /$ ijpr.2019.198

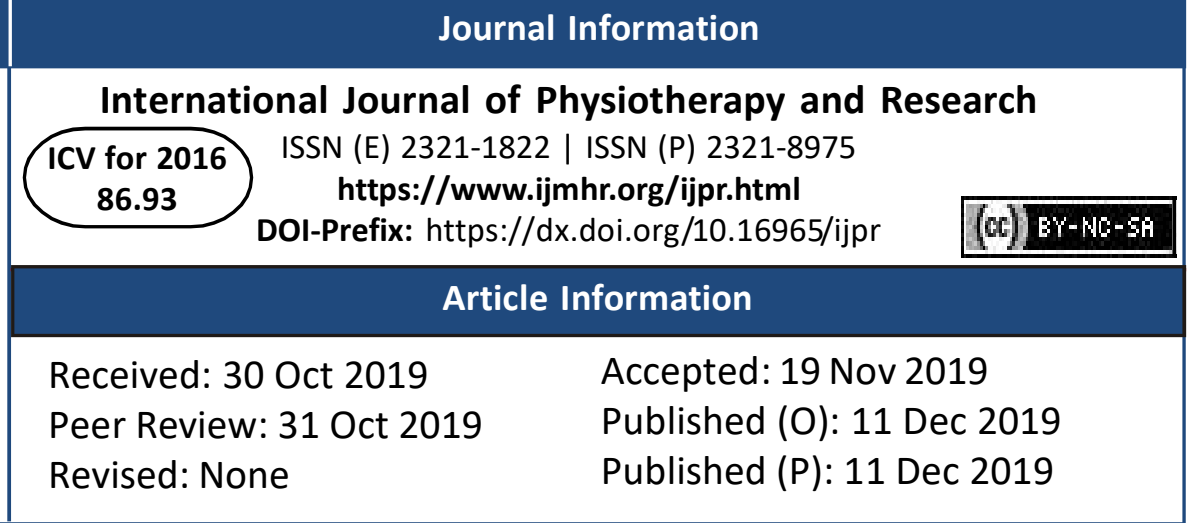

informed interpretation as its core [1]. Physiotherapy is the one of the oldest profession in healthcare practiced since $460 \mathrm{Bc}$ by great physicians such as Hippocrates and Galen. Events such as First World War, Polio- outbreak, increasing disabilities lead to rapid progression and modernization of physiotherapy from $18^{\text {th }}$ century [2].

In India Physiotherapy treatment became evident in the year 1952, due to outbreak of Poliomyelitis in Mumbai. In 1953, first Physiotherapy school and Centre was established in Seth G.S Medical College and K.E.M Hospital as 
joint collaborative venture by Government of India and Brihanmumbai Municipal Corporation (BMC) with support from WHO [3].

There has been a tremendous improvement in physiotherapy treatment with more of evidence based quality health services. Physical therapists as a part of the health care team play an essential role in reducing hospital stay, in providing a quicker recovery, and in rehabilitation for a better qual-ity life [4].

Women dwelling in an apartment or community usually ignore their health. In case they think of health they prefer physicians. They usually have nominal idea about wonders of physiotherapy.

With this survey I wanted to get an insight into how much Indian women know about physiotherapy and its benefits.

\section{MATERIALS AND METHODS}

A survey was conducted online using social media in the form of questionnaire which had open ended and closed ended questions. The questionnaire was submitted using Google forms to all using a link shared via social media, (Whatsapp, Facebook, Gmail) for a period of one week. Responses were obtained and analyzed.

RESULTS
Results were calculated directly by Google spreadsheet in terms of frequency distribution and descriptive statistics. The study was conducted on a sample of 110 women in a community setting in Bangalore.

Response rate: The questionnaire was distributed to 110 respondents. All the 110 respondents completed the questionnaire and returned to the researcher on the same day (Response rate: $100 \%)$

Awareness about Physiotherapy: It was good to get in the results that $79 \%$ of women who participated in the survey had knowledge about physiotherapy. Physiotherapy is an emerging profession, more the people are aware more people can get benefitted by physiotherapy services.

Most of the respondents in my study belong to 30-39 years age group.

Women who received Physiotherapy: From the data collected, $67 \%$ of women received some form of physiotherapy treatment in their lives. But though most of them were not that clear about the type of treatment they received.

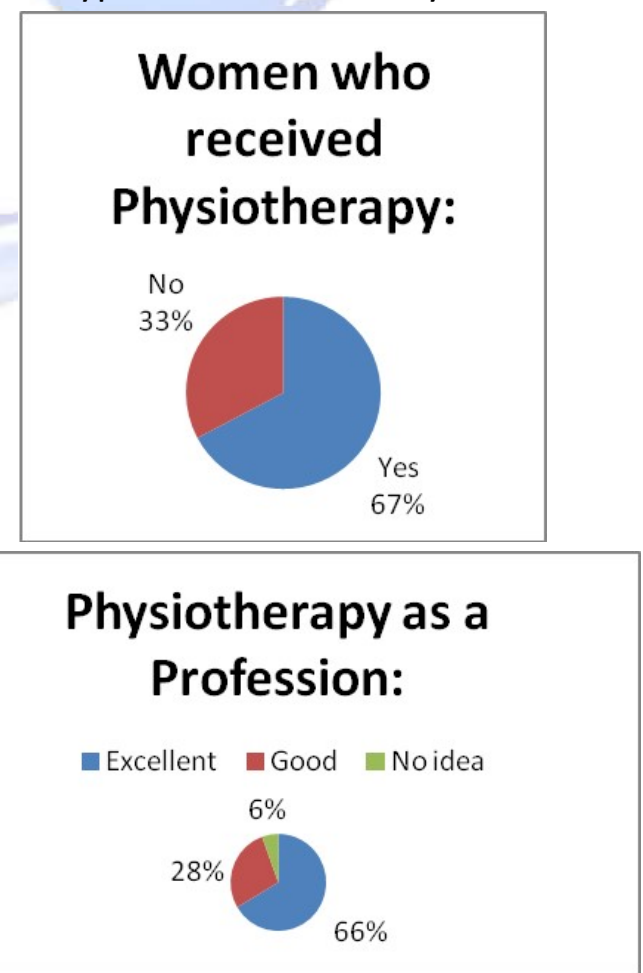

Physiotherapy as a Profession: $66 \%$ of respondents who had idea about Physiotherapy feel that as a profession Physiotherapy was excellent. With the increasing number of somatic pain, postural abnormalities \& obesity it is a good career option. 


\section{Scope of Physiotherapy services}

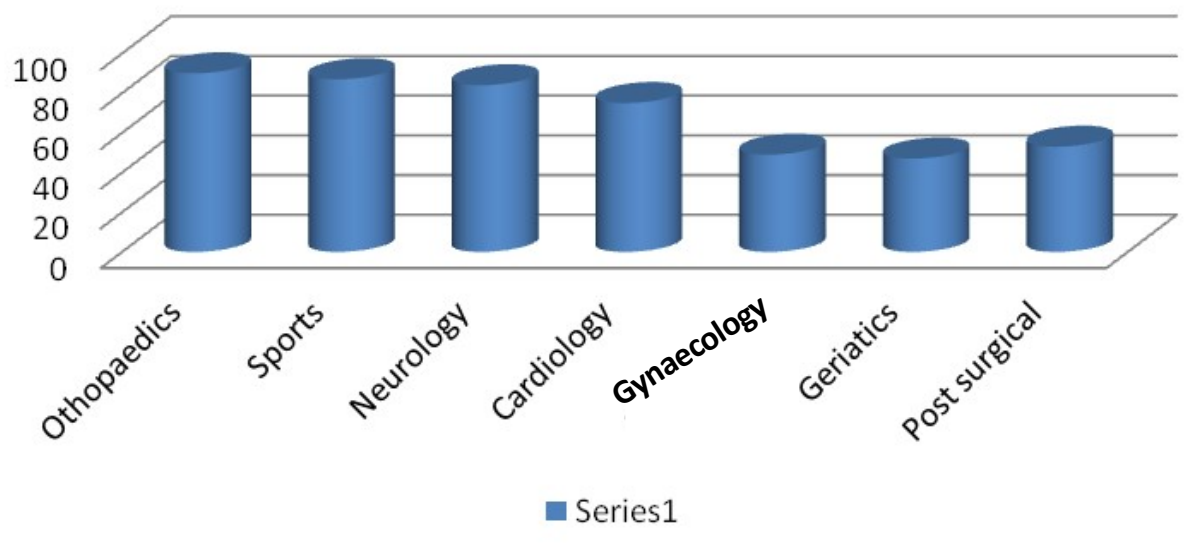

Scope of Physiotherapy: Most of the respondents had idea that Physiotherapists can treat Orthopaedic \& Sports injury. On being asked regarding role of physiotherapy in Pregnancy, Labour, geriatrics they had minimal ideas.

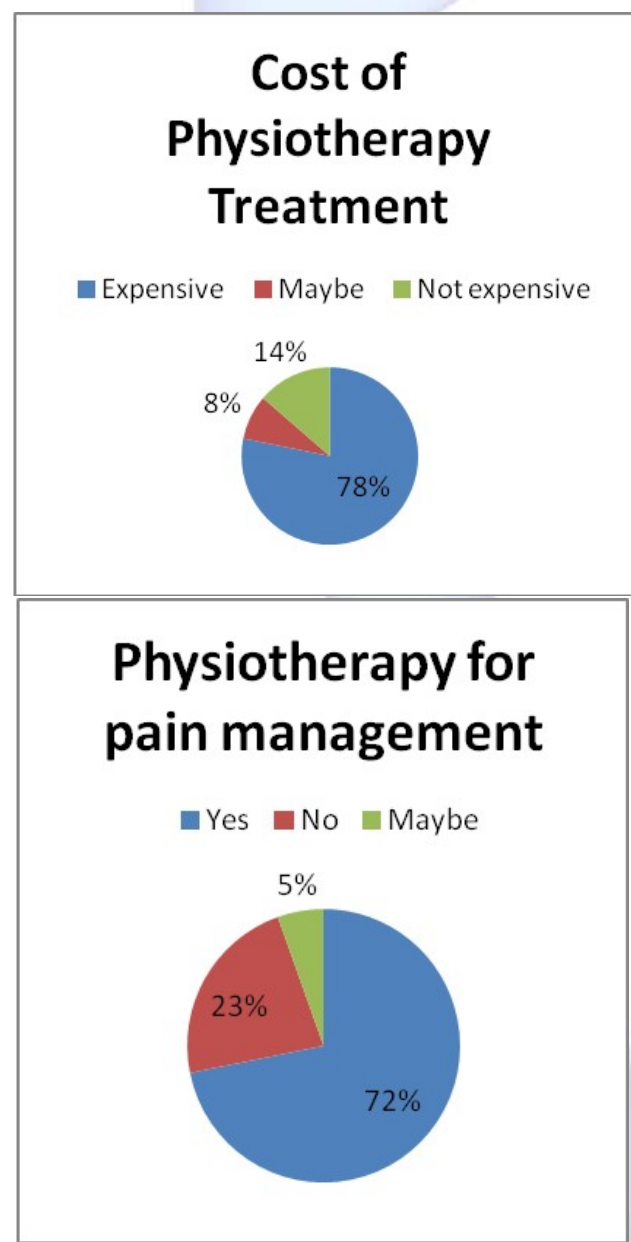

Cost of Physiotherapy treatment: about 78\% of the respondent feel that physiotherapy services are too expensive for middle class people to afford. While $14 \%$ had no idea whether they paid the right amount for the services they availed.
Physiotherapy for pain management: $72 \%$ of respondent are aware \& feel that physiotherapy is an excellent way for pain management. $27 \%$ feel physiotherapy doesnot deal with pain management.

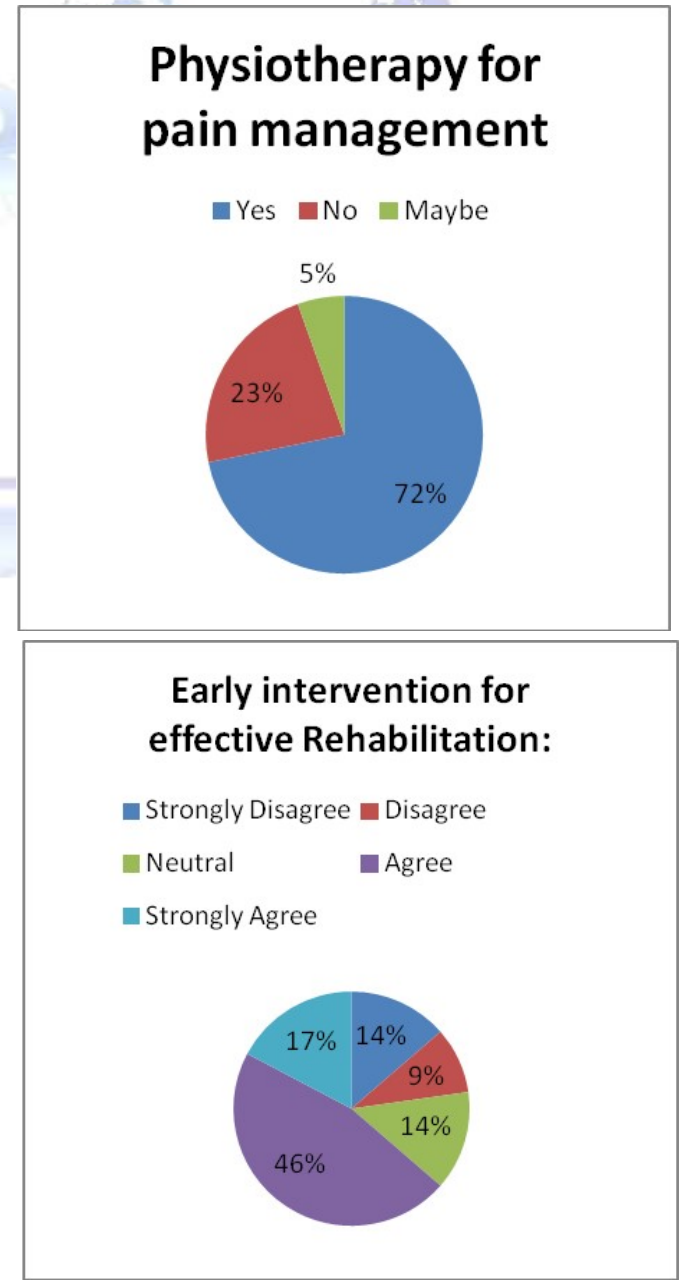

Early intervention for effective rehabilitation: $46 \%$ of respondents strongly agree that with early intervention of physiotherapy, rehabilitation process gets accelerated. Whereas $14 \%$ of respondents didn't agree with this concept. 


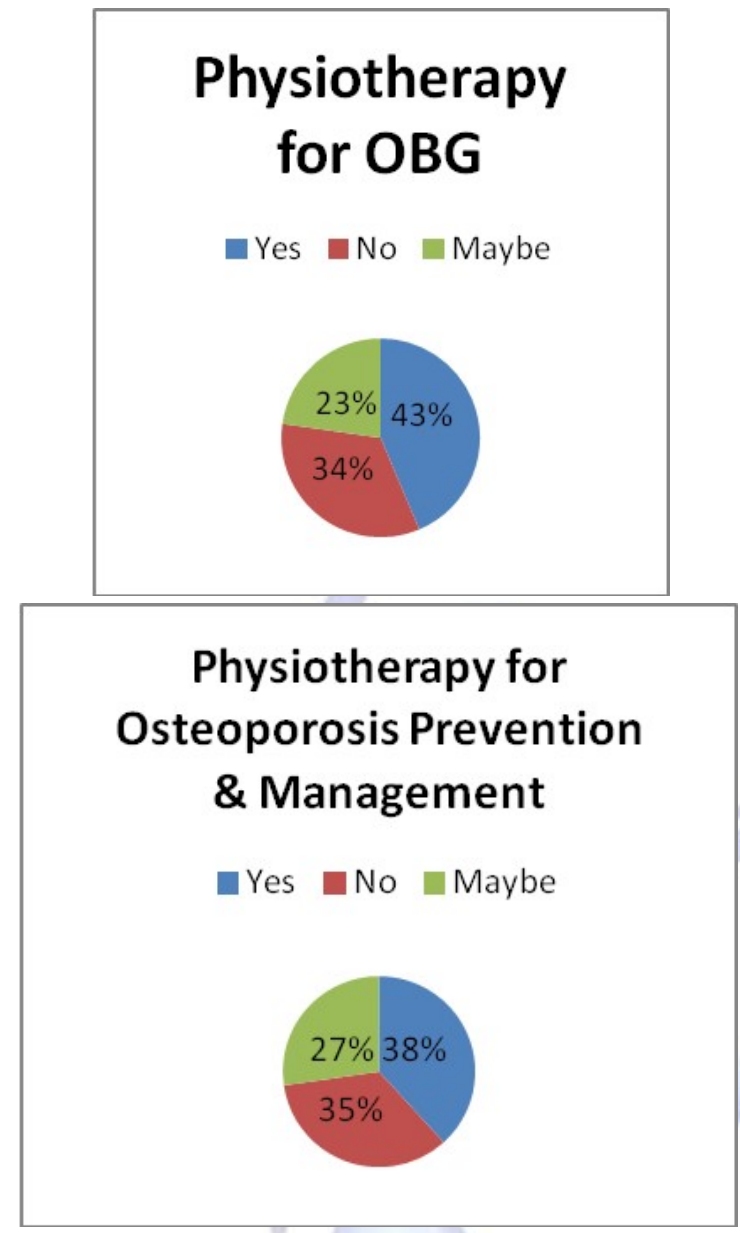

Physiotherapy for OBG: $43 \%$ of women had some idea that physiotherapy can help women in their pregnancy. But few had minimal idea about role of physiotherapy in labour \& during post natal period. $30 \%$ of respondents feel physiotherapy has no role in OBG.

Physiotherapy for Osteoporosis Prevention \& Management: $38 \%$ of respondents are aware of the impact of physiotherapy in prevention and management of osteoporosis. 275 were unsure of osteoporosis and role of physiotherapy in such case

\section{Physiotherpy for Urinary Incontinence:}

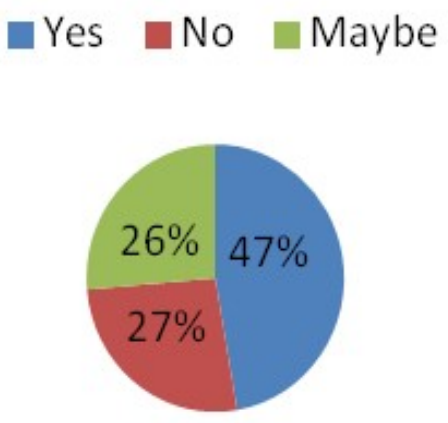

Physiotherapy for Urinary Incontinence: It was a good response that about $47 \%$ of women respondents were aware of the fact that regular Kegel's exercises made tremendous impact on the pelvic floor muscles of women.

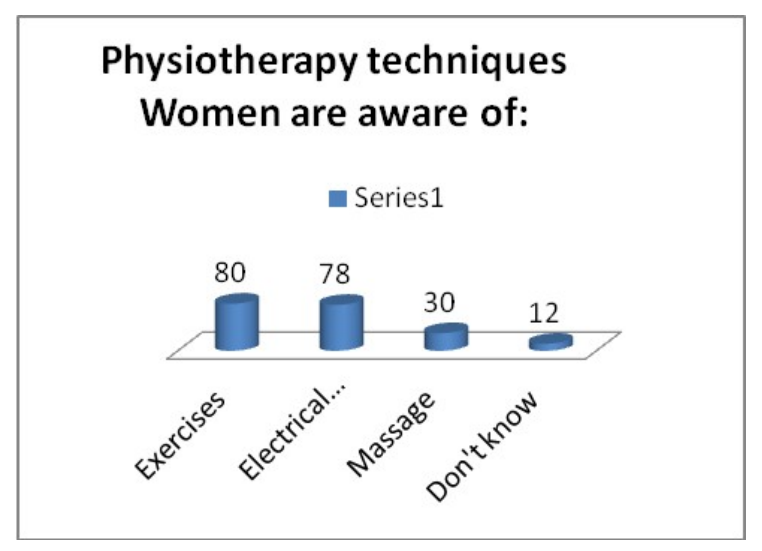

\section{Source of Physiotherapy information:}

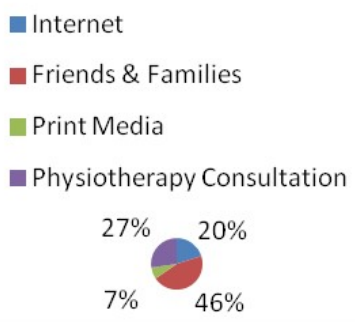

Source of Physiotherapy information: Around $46 \%$ of respondents found their first information about Physiotherapy from Friends \& families who had one undergone physiotherapy treatment. Print media as a source of information for physiotherapy was negligible accounting to only $7 \%$.

\section{DISCUSSION}

The survey helped to understand the existing level of awareness about physiotherapy and its scope / areas of intervention amongst women in a community setting. Though women were aware about physiotherapy in a vague manner but specific scopes and areas where physiotherapy can benefit women was still mearge. Women these days have also received some form of physiotherapy, though couldn't specify the type. They also expressed in the survey that, physiotherapy as a profession was excellent. They would definitely consider it for their kids in future. All these indicate a growing awareness about physiotherapy.

Most of the respondents did feel physiotherapy treatment being expensive so it was not feasible for them to avail it. In general they also 
felt the major part of physiotherapy treatment was exercises and electrical modalities. They also feel that physiotherapy majorly deals with orthopedic, sports injuries \& certain neurological conditions.

Most respondents also were aware that physiotherapy does help in pain management. According to a study conducted by Lorimer Moseley [5], combined physiotherapy treatment and patient education produced symptomatic and functional change in moderately disabled chronic low back pain patients.

While most of the respondents were not aware of the specific areas like antenatal, post natal role of physiotherapy, role of physiotherapy in prevention and management of osteoporosis, or role of physiotherapy in management of urinary incontinence. As per the study conducted by Margaret Sherburn [6] pelvic floor muscle training during pregnancy facilitates, rather than obstructs, labour. As per the study by Licia Santos Santana ${ }^{7}$ TENS (Transcutaneous Electrical Nerve Stimulation) reduces pain and postpones the need for pharmacological need for analgesia during labour. According to a study by Neumann.P et all ${ }^{8}$ an effective program showed increased contractile strength as well as increased resting tone of pelvic floor, which improved support of pelvic organs higher in the pelvis.

\section{CONCLUSION}

There has been studies about awareness of physiotherapy in general population, in medical interns and higher secondary students. My purpose of this survey was to find out how well women know about physiotherapy and what to expect from physiotherapy services. The respondents had awareness about physiotherapy but awareness about the role of Physiotherapy in specialties other than orthopaedics and sports is not satisfactory, There is a felt need to create more specific understanding and promote utilization of services to promote quality of life. Once they are aware, they can help make their lives better and prevent themselves from multiple age related degenerative conditions. This study can be studied in a large scale and the factors attributing to the awareness can be studied.

\section{Conflicts of interest: None}

\section{REFERENCES}

[1]. Chartered Society of Physiotherapy."What is Physiotherapy?". Chartered Society of Physiotherapy. http://www.csp.org.uk/director/public/ whatphysiotherapy.cfm. Retrieved 2010-07-10

[2]. Physical therapy [Internet]. En.wikipedia.org. 2016 [cited 16 December 2016]. Available from: https:// en.wikipedia.org/w/index.php? title= Physical_therapy\&oldid $=754009927$

[3]. Shimpi A, Writer H, Shyam A, Dabadghav R. Role of Physiotherapy in India - Role of Physiotherapy in India-A Cross-sectional Survey to Study the Awareness and Perspective among Referring Doctors. Journal Medical Thesis 2014 May-Aug; 2(2):11-15.

[4]. Lasswell A, Smith SR. Attitudes of medical students and physician faculty members toward nonphysi-cian health professionals. Academic Medicine. 1987;62(6):509-11.

[5]. Moseley L. Combined physiotherapy and education is efficacious for chronic low back pain. Australian Journal of Physiotherapy 2002;48:297-302.

[6]. Margaret Sherburn. Pelvic floor muscle training during pregnancy facilitates labour. Australian Journal of Physiotherapy 2004;50(4):258.

[7]. Licia Santos Santana et al. Transcutaneous electrical nerve stimulation (TENS) reduces pain and postpones the need for pharmacological analgesia during labour: a randomised trial. Journal of Physiotherapy, 2016;62(1):29-34.

[8]. Neumann, P and Morrison, S. Physiotherapy for urinary incontinence [online]. Australian Family Physician, 2008;37(3):118-21.

How to cite this article:

Smruti Swagatika Dash. AWARENESS OF PHYSIOTHERAPY \& ITS SCOPE AMONG WOMEN IN A COMMUNITY- A SURVEY. Int J Physiother Res 2019;7(6):3331-3335. DOI: 10.16965/ijpr.2019.198 